\title{
Phenozan Influence on the Physiological-Biochemical Parameters of the Young Minks Leading to Their Advanced Properties
}

\author{
Nikolai A. Balakirev, ${ }^{1}$ Sergei Yu. Zaitsev, ${ }^{2}$ and Albert A. Rizvanov ${ }^{3}$ \\ ${ }^{1}$ Animal Zootechnology Department, Federal State Budgetary Educational Institution of Higher Education, \\ "Moscow State Academy of Veterinary Medicine and Biotechnology-MVA by K.I. Skryabin", Akad. Skryabin Str. 23, \\ Moscow 109472, Russia \\ ${ }^{2}$ Chemistry Department, Federal State Budgetary Educational Institution of Higher Education, \\ "Moscow State Academy of Veterinary Medicine and Biotechnology-MVA by K.I. Skryabin", Akad. Skryabin Str. 23, \\ Moscow 109472, Russia \\ ${ }^{3}$ Institute of Fundamental Medicine and Biology, Kazan Federal University, Kazan, Russia
}

Correspondence should be addressed to Sergei Yu. Zaitsev; s.y.zaitsev@mail.ru

Received 22 April 2016; Revised 3 August 2016; Accepted 16 August 2016

Academic Editor: Iain J. McGaw

\begin{abstract}
Copyright (C) 2016 Nikolai A. Balakirev et al. This is an open access article distributed under the Creative Commons Attribution License, which permits unrestricted use, distribution, and reproduction in any medium, provided the original work is properly cited.
\end{abstract}

\begin{abstract}
The antioxidant influence on the physiological-biochemical parameters of productive animals is one of the most important directions in modern animal science. Phenozan is a synthetic antioxidant with high biological activities including those for animals. The positive effects of phenozan on the physiological-biochemical parameters of the mink blood were found. These effects are leading to the intensive growth, strong health, enhancement of the mink fur quality, and so forth. The total amount of the erythrocytes in the mink blood increased by about $4-5 \%$ due to phenozan inclusion in the mink diet. Even a more significant increase was found in hemoglobin content in the mink blood and erythrocytes (by about $9.5 \%$ and $8.8 \%$, resp.) due to phenozan inclusion of $100 \mathrm{mg} / \mathrm{day}$, whereas it was found only by about $6.1-5.3 \%$ or $5.5-0.3 \%$, owing to phenozan inclusion of $50 \mathrm{or} 150 \mathrm{mg} / \mathrm{day}$. For many other parameters the optimal phenozan concentration was about $100 \mathrm{mg} /$ day per head according to the result obtained for all studied animal groups. Thus, phenozan can be successfully used as a biologically active compound for mink nutrition and is recommended for other farm animals.
\end{abstract}

\section{Introduction}

Antioxidants are intensively studied biologically active compounds (BACs) important for all animals and humans. They can be divided into two groups: natural (so-called "bioantioxidants") and synthetic (preferably containing "shielded" phenol group) antioxidants as discussed elsewhere [1-6]. Natural antioxidants are some vitamins, coenzymes, monosodium glutamate, selenium, glutathione, and so forth. The examples of the synthetic antioxidants are the following: ionol, diludin, santohin, phenozan, phenoksan, and so forth. They have various functions: from direct participation in metabolic processes to prevention of some diseases. The major biological function of antioxidants includes the interactions with various oxygen forms: antiradical action (tocopherol, phenol), peroxide destruction (selenium, sulfur-containing compounds), and interaction with some metal ions or inactivation of the highly reactive singlet oxygen (vitamin A, carotenoids) as discussed elsewhere [1, 2, 5-7]. High efficiency of antioxidants, above all, is due to their membraneprotective action. This plays a great role in the prevention and correction of membranes damage by various pathologies, for example, inhibition of the fat oxidation by molecular oxygen $[1,8]$. 
Modern directions in the biological and veterinary sciences include the study of the antioxidant influence on the morphological-biochemical parameters of various farm animals. The use of antioxidant in animal nutrition leads to an increase in their "zootechnical" characteristics: intensive growth, strong health, enhancement of meat and milk production, and so forth. Along with previously known antioxidants a great attention is devoted to the design and testing of the novel BAC such as so-called phenozan acid or simply phenozan [9-11]. Phenozan and other phenolic antioxidants were synthesized; their physical-chemical and general biological properties were characterized in the Emanuel Institute of Biochemical Physics of Russian Academy of Sciences (IBCP RAS). Numerous works [9-11] have proved wide biological activity of phenozan and some other phenolic antioxidants. It is important to underline that prior to the beginning of our work there had been limited data on the phenozan effects on farm animals $[10,11]$, especially its influence on the most important morphological-biochemical parameters of animal tissues and organs.

Currently, antioxidants are used in animal breeding as growth promoters, to increase resistance, stress reduction, to stabilize unsaturated fatty compounds and vitamins, by direct feeding to animals $[1,2,11-16]$. They are also involved in the process of tissue respiration, and they are permanent components of membrane structures regulating their permeability and stability $[1,8]$. Before the beginning of our research there had been no reliable data on the phenozan influence on the parameters of minks as typical fur animals.

The present study was undertaken to test the phenozan influence on the physiological-biochemical parameters of young minks and to obtain the correlations with their "zootechnical" characteristics.

\section{Material and Methods}

Phenozan was synthesized and characterized in the Emanuel Institute of Biochemical Physics of Russian Academy of Sciences (IBCP RAS) as published previously [10, 11]. The animal experiments took place on the "Koschakovsky" minkbreeding farm. All procedures were carried out with the approval of the Animal Care Committee of the Federal State Budgetary Educational Institution of Higher Education "Moscow State Academy of Veterinary Medicine and Biotechnology-MVA by K.I. Skryabin" according to the international guidelines.

The minks were subdivided into four groups (56 heads in each group): (I) control group (no phenozan in their diet) and three experimental groups of minks fed with phenozan: (II) $50 \mathrm{mg} /$ day per head, (III) $100 \mathrm{mg} /$ day per head, and (IV) $150 \mathrm{mg} /$ day per head (for the period of 72 days). The blood for investigation was taken before feeding by standard methods [1]. Plasma was stored at the temperature of $4-8^{\circ} \mathrm{C}$ for 6 hours. If longer storage was required, it was frozen and stored at $-20^{\circ} \mathrm{C}$. Blood serum was obtained by settling whole blood and retraction of the clot followed by centrifugation. The serum was centrifuged at $2000 \mathrm{rpm}$ during $10-15 \mathrm{~min}$. The major hematological (total erythrocytes, hemoglobin, hematocrit, HCE as hemoglobin concentration in the erythrocytes media, MCV as mean cell volume, $\mathrm{MCH}$ as mean cell hemoglobin, and platelets) and biochemical (total proteins, lipids, etc.) parameters in the mink serum were measured by standard methods [8] based on the microscopy or spectroscopy of a mixture of the serum sample and appropriate reagent (all was incubated at $37^{\circ} \mathrm{C}$ during 1-3 min.). The electrophoresis in the polyacrylamide gel (according to the standard protocol [8]) was used to determine the content of protein fractions in the mink serum (albumin and globulin fractions, in percentage, and their ratio, in arbitrary units). The statistical analysis software was used for statistical treatment of the obtained data. Experimental data were treated by variation statistics methods; in particular, the differences of the measured parameters from one another and from the normal level were estimated using Student's test [1].

\section{Results and Discussion}

The influence of the phenozan (included into the mink diet) on the major physiological-biochemical and "zootechnical" parameters of these animals has been studied taking into account an important biological role of such antioxidants in the animal metabolism. In the preliminary microbiological tests the phenozan doses equal to $25,50,75,100,150,200,250$, and $350 \mathrm{mg} /$ day were studied on various cell lines (human breast carcinoma HBL-100, human keratinocytes HaCaT, human epithelial carcinomas A431, and canine kidney epithelial cells MDCK) [1, 17]. These tests allowed determining the optimal dose range (from 50 to $150 \mathrm{mg}$ /day) for further experiments on animals without all dose-tests. The additional experiments would be rather expensive taking into account that for 3 dose-tests and control groups we used in total 224 healthy productive minks.

First, the total amount of the erythrocytes in the mink blood increased by about $4-5 \%$ by phenozan inclusion (in amount 50, 100, and $150 \mathrm{mg} /$ day) in the mink diet and was almost the same for all experimental groups (Table 1). Even a more significant increase was found for hemoglobin content in the mink blood and erythrocytes (by about $9.5 \%$ and $8.8 \%$, resp.) due to phenozan inclusion of $100 \mathrm{mg} /$ day (group III), whereas it was found only by about $6.1-5.3 \%$ or $5.5-0.3 \%$, owing to phenozan inclusion of 50 or $150 \mathrm{mg} /$ day (group II or IV, resp.). Thus, the phenozan inclusion in the mink diet had positive influence on the blood cell and hemoglobin metabolism for young minks.

The hemoglobin concentration in the erythrocytes media (HCE) increased gradually along with increasing phenozan amount in the mink diet (by about $3.8 \%, 5.5 \%$, or $8.3 \%$ in group II, III, or IV as compared to group I, resp.). In contrast, mean cell volume (MCV) of the single erythrocyte decreased gradually along with increasing phenozan amount in the mink diet (by about $-2.4 \%,-6.1 \%$, and $-9.9 \%$ in group II, III, or IV, resp.).

It was unexpected that the inclusion of various phenozan doses into the diet was not accompanied by significant changes in the hematocrit, the "mean cell hemoglobin" 
TABLE 1: Major parameters of the minks blood samples taken from the control (I) and experimental (II-IV) animal groups (received phenozan).

\begin{tabular}{|c|c|c|c|c|}
\hline \multirow[b]{2}{*}{ Parameters } & \multicolumn{4}{|c|}{ Groups } \\
\hline & $\begin{array}{c}\mathrm{I} \\
\text { (control) }\end{array}$ & $\begin{array}{c}\text { II } \\
\text { (50 mg/day) }\end{array}$ & $\begin{array}{c}\text { III } \\
(100 \mathrm{mg} / \text { day })\end{array}$ & $\begin{array}{c}\text { IV } \\
(150 \mathrm{mg} / \text { day })\end{array}$ \\
\hline Total erythrocytes, $10^{12}$ per liter & $9.5 \pm 0.1$ & $10.0 \pm 0.5$ & $10.0 \pm 0.5$ & $9.9 \pm 0.2$ \\
\hline \multicolumn{5}{|l|}{ Hemoglobin, g/L } \\
\hline In blood & $174.0 \pm 3.3$ & $184.6 \pm 7.3^{*}$ & $190.6 \pm 4^{*}$ & $183.2 \pm 4^{*}$ \\
\hline In erythrocytes & $285.4 \pm 30.4$ & $301.2 \pm 4.2^{*}$ & $310.6 \pm 4.5^{*}$ & $284.6 \pm 14.0^{*}$ \\
\hline Plasma & $16.0 \pm 4.1$ & $12.5 \pm 3.4$ & $19.8 \pm 3.3$ & $35.0 \pm 9.4$ \\
\hline Hematocrit, \% & $55.4 \pm 0.4$ & $57.2 \pm 1.3$ & $55.0 \pm 0.9$ & $55.2 \pm 1.9$ \\
\hline HCE, \% & $31.4 \pm 0.4$ & $32.6 \pm 0.4$ & $33.0 \pm 2.0$ & $35.6 \pm 0.6$ \\
\hline $\mathrm{MCH}, \mathrm{pg} /$ cell & $18.4 \pm 0.3$ & $15.0 \pm 2.1$ & $19.0 \pm 0.6$ & $18.4 \pm 0.4$ \\
\hline $\mathrm{MCV}, \mathrm{fL}$ & $58.4 \pm 0.6$ & $57.0 \pm 1.5$ & $54.8 \pm 1.3^{*}$ & $52.6 \pm 1.8^{*}$ \\
\hline Platelets, $10^{9}$ per liter & $595.8 \pm 75.4$ & $686.6 \pm 59.8$ & $599.6 \pm 111,0$ & $569.2 \pm 128.3$ \\
\hline Total lipids, mg/dL & $17.1 \pm 2.5$ & $16.8 \pm 0.9$ & $18.6 \pm 0.8$ & $17.6 \pm 0.3$ \\
\hline
\end{tabular}

${ }^{*} p<0.05$.

TABLE 2: Basic indicators of the "protein spectrum" of mink blood samples taken from the control (I) and experimental (II-IV) animal groups (received phenozan).

\begin{tabular}{|c|c|c|c|c|}
\hline \multirow{2}{*}{ Parameters } & \multicolumn{4}{|c|}{ Groups } \\
\hline & I (control) & II & III & IV \\
\hline Total protein, g/L & $123.4 \pm 2.5$ & $126.2 \pm 3.6$ & $130.4 \pm 3.0^{*}$ & $125.6 \pm 3.2$ \\
\hline Albumins (A), g/L & $46.8 \pm 1.7$ & $45.6 \pm 3.5$ & $47.7 \pm 2.3$ & $47.2 \pm 1.7$ \\
\hline \multicolumn{5}{|l|}{ Globulin fractions, $\%$} \\
\hline Total globulins (G) & $53.2 \pm 1.7$ & $54.4 \pm 3.3$ & $52.3 \pm 2.3$ & $52.8 \pm 1.7$ \\
\hline \multicolumn{5}{|l|}{ Including } \\
\hline$\alpha$ & $15.5 \pm 0.6$ & $16.3 \pm 0.4$ & $16.7 \pm 1.8$ & $16.9 \pm 1.0$ \\
\hline$\beta$ & $13.4 \pm 0.5$ & $15.9 \pm 1.7$ & $13.1 \pm 0.4$ & $12.6 \pm 0.8$ \\
\hline$\gamma$ & $24.1 \pm 1.0$ & $22.4 \pm 1.8$ & $22.5 \pm 2.1$ & $23.3 \pm 1.2$ \\
\hline The ratio $A / G$, a.u. ${ }^{* *}$ & 0.88 & 0.84 & 0.91 & 0.89 \\
\hline
\end{tabular}

${ }^{*} p<0.05,{ }^{* *}$ arbitrary units.

$(\mathrm{MCH})$, or the average mass of hemoglobin per single erythrocyte (with only negligible difference for group II). The phenozan influence on the platelets (also called "thrombocytes") amount was nonlinear: firstly, drastic increase happens by addition of the relatively small phenozan amount (by $15.2 \%$ from groups I to II); secondly, this led to almost the same values between groups III and I; thirdly, by addition of the high phenozan amount (group IV) the pronounced decrease of the platelets amount (by $-4.5 \%$ ) was found. The last dependence can be explained by particular changes in the blood cell and coagulation systems. Thus, in major cases the phenozan influence had positive influence on the morphological parameters of mink blood that was useful for the administration of antioxidants into the animal diet. Obviously, the phenozan influence on the above mentioned parameters will need further evaluation that is on track.

On the other hand the phenozan inclusion in amount of $100 \mathrm{mg} /$ day into the mink diet (group III) is optimal for the general positive effect. This can be proved by the significant increase of the total lipid content in the blood for group III (on $8.8 \%$ ) as compared to the control and other experimental groups.

The observed effects were especially pronounced in the case of the protein metabolism. Proteins play an important role in the vital activity of any living organism. In normal conditions, proteins in the body are constantly in the metabolic dynamic equilibrium. The most studied and informative for the analysis of the animal biochemical status are plasma proteins. On this basis, we found it necessary first to examine the changes in the total amount of the plasma proteins of minks fed with phenozan (Table 2). There was a small increase found in the case of the total protein content for groups II and IV as compared to the control group, whereas a more pronounced increase (by 5.7\%) was found in the case of group III as compared to all other groups (Table 2). Almost the same positive peculiarities were observed for albumin fraction that proved the optimal phenozan inclusion in amount of $100 \mathrm{mg}$ /day into the mink diet (group III). Albumins as major plasma proteins performed some essential functions, such as the support of the colloid-osmotic pressure, and transport a 
TABLE 3: Major parameters of the minks hormones taken from the control (I) and experimental (II-IV) animal groups (received phenozan).

\begin{tabular}{lcccc}
\hline & & & Groups & \\
Parameters & I & II & III & IV \\
& (control) & $(50 \mathrm{mg} / \mathrm{day})$ & $54.90 \pm 6.70^{*}$ & $(150 \mathrm{mg} / \mathrm{day})$ \\
\hline$T_{4}, \mathrm{nmol} / \mathrm{g}$ & $48.07 \pm 5.62$ & $44.13 \pm 5.43$ & $1.30 \pm 0.11$ & $40.50 \pm 3.07^{*}$ \\
$T_{3}, \mathrm{nmol} / \mathrm{L}$ & $1.40 \pm 0.12$ & $1.46 \pm 0.11$ & $44.73 \pm 3.73^{*}$ & $1.25 \pm 0.13$ \\
IRI, $\mathrm{mU} / \mathrm{mL}$ & $34.74 \pm 4.08$ & $35.66 \pm 4.37$ & & $37.44 \pm 3.52$ \\
\hline
\end{tabular}

${ }^{*} p<0.05$.

TABLE 4: Major parameters of the inner minks organs taken from the control (I) and experimental (II-IV) animal groups (received phenozan).

\begin{tabular}{|c|c|c|c|c|}
\hline \multirow[b]{2}{*}{ Organs } & \multicolumn{4}{|c|}{ Groups } \\
\hline & $\begin{array}{c}\mathrm{I} \\
\text { (control) }\end{array}$ & $\begin{array}{c}\text { II } \\
(50 \mathrm{mg} / \text { day })\end{array}$ & $\begin{array}{c}\text { III } \\
(100 \mathrm{mg} / \text { day })\end{array}$ & $\begin{array}{c}\text { IV } \\
\text { (150 mg/day) }\end{array}$ \\
\hline Carcass, $g$ & $1343.1 \pm 80.4$ & $1352.5 \pm 48.4$ & $1332.5 \pm 66.6$ & $1355.0 \pm 28.7$ \\
\hline Heart, g & $12.9 \pm 0.5$ & $12.2 \pm 0.6$ & $13.7 \pm 1.2$ & $14.1 \pm 0.7$ \\
\hline Stomach, $g$ & $10.1 \pm 0.7$ & $12.2 \pm 0.7$ & $9.8 \pm 0.7$ & $11.9 \pm 0.9$ \\
\hline Liver, $\mathrm{g}$ & $48.3 \pm 2.4$ & $51.4 \pm 3.9^{*}$ & $60.7 \pm 3.1^{*}$ & $55.0 \pm 3.5^{*}$ \\
\hline Kidneys, g & $8.8 \pm 0.2$ & $10.5 \pm 0.7$ & $10.2 \pm 0.4$ & $9.8 \pm 0.3$ \\
\hline Spleen, g & $2.6 \pm 0.2$ & $3.5 \pm 0.4$ & $3.2 \pm 0.3$ & $2.8 \pm 0.2$ \\
\hline Thyroid gland, mg & $44.3 \pm 5.3$ & $72.0 \pm 7.5^{*}$ & $84.0 \pm 17.3^{*}$ & $57.0 \pm 6.3^{*}$ \\
\hline Lungs, $g$ & $15.7 \pm 1.5$ & $19.2 \pm 1.6$ & $16.8 \pm 1.0$ & $17.9 \pm 1.7$ \\
\hline Intestines, $\mathrm{g}$ & $36.3 \pm 0.9$ & $47.5 \pm 2.0^{*}$ & $41.3 \pm 1.9^{*}$ & $39.7 \pm 1.1^{*}$ \\
\hline $\begin{array}{l}\text { Ratio of the whole body length to the } \\
\text { intestines length, a.u. }\end{array}$ & 4.4 & 4.2 & 4.6 & 4.6 \\
\hline
\end{tabular}

${ }^{*} p<0.05$.

number of insoluble components in the plasma. Total plasma globulin amount did not change gradually, probably, due to their complex composition. It is well known that the plasma globulins can be divided into a number of fractions, the percentage of which may also vary depending on the age of the animals and other factors [8]. By globulin fractions analysis one can conclude that only $\alpha$-fraction level has linear correlation with the phenozan amount included in the mink diet (Table 2). The level of the $\alpha$-fraction globulins increased pronouncedly by addition of the relatively small phenozan amount (on $5.2 \%$ from groups I to II) and also by further phenozan addition (on $7.7 \%$ and $9.0 \%$ as compared to the control group) (Table 2).

Actually, the ratio between albumins and globulins (A/G) is the most informative. In this case, a particular decrease was found for group II as compared to the control, whereas the pronounced increase was found for group III as compared to all other groups (Table 2). Being in close contact with the proteins of various tissues, blood proteins subtly react to changes in the biochemical processes occurring in the organism. The results showed that phenozan inclusion in different doses had particular influence on the protein composition of animal blood.

These data were supported by some hormones study for these minks. The maximal $T_{4}$ and IRI values (54.90 \pm $6.70 \mathrm{nmol} / \mathrm{g}$ and $44.73 \pm 3.73 \mathrm{mU} / \mathrm{mL}$, resp.) and the minimal $T_{3}$ value $(1.30 \pm 0.11 \mathrm{nmol} / \mathrm{L})$ were found in the case of group II (Table 3 ). So, radioimmunoassay measurements of some hormones levels in the minks blood proved that the most significant changes in hormonal status were observed for animals treated with $100 \mathrm{mg}$ of phenozan per day (i.e., concentration of $T_{4}$ and IRI increased by $14.2 \%$ and $28.7 \%$, whereas the $T_{3}$ value decreased by $10.7 \%$ ).

In order to determine the further effect of phenozan additives on the animals, the necessity of morphological studies of their internal organs appeared. The analysis showed that the major parameters of the inner organs of the animals in the experimental (II-IV) groups (received phenozan) were in the same normal physiological range as those of the animals in control group I (Table 4). In addition, a tendency to the increase of the weight of thyroid glands, as well as the weight and length of the intestine, was found for all experimental animals in comparison with the control (Table 4). Taking into account that the mass of minks before slaughter was higher during the phenozan inclusion in mink diets, it was of interest to find out the difference in the measurement of animal weight and their fell dimensions. The analysis of the data indicated that mink weight ranged from $2005 \mathrm{~g}$ (control) to about 2065-2075 $\mathrm{g}$ (all experimental groups). These data correlated with the increase in the lengths of the mink body (by $1.4-1.6 \mathrm{~cm}$ higher for experimental groups as compared to the control) and of the chest girth (by $2-3 \mathrm{~cm}$, resp.). Apparently, the use of phenozan in mink diets activated the metabolic processes in young animals during the period of intensive growth, which finally led to the increase of the linear dimensions of the body and the fur 
TABLE 5: Some parameters of the minks, essential for commercial characteristics.

\begin{tabular}{|c|c|c|c|c|}
\hline \multirow[b]{2}{*}{ Parameters } & \multicolumn{4}{|c|}{ Groups } \\
\hline & $\begin{array}{c}\mathrm{I} \\
\text { (control) }\end{array}$ & $\begin{array}{c}\text { II } \\
\text { (50 mg/day) }\end{array}$ & $\begin{array}{c}\text { III } \\
(100 \mathrm{mg} / \text { day })\end{array}$ & $\begin{array}{c}\text { IV } \\
(150 \mathrm{mg} / \text { day })\end{array}$ \\
\hline Fells dimension $A, \%$ & 43.7 & 69.0 & 61.5 & 51.1 \\
\hline Fells dimension $B, \%$ & 52.1 & 28.6 & 36.5 & 46.7 \\
\hline Fells dimension $C, \%$ & 4.2 & 2.4 & 2.0 & 2.2 \\
\hline No defects, \% & 47.9 & 45.2 & 48.1 & 44.4 \\
\hline Small defects, $\%$ & 37.5 & 38.1 & 32.7 & 46.7 \\
\hline Middle defects, \% & 12.5 & 14.3 & 19.2 & 6.7 \\
\hline Large defects, $\%$ & 2.1 & 2.4 & 0 & 2.2 \\
\hline Quality score, a.u. & 115.7 & 118.5 & 118.6 & 117.6 \\
\hline Price increase (as compared to group I), \% & - & 2.8 & 3.9 & 2.1 \\
\hline
\end{tabular}

area. These data are in agreement with the results obtained for some other antioxidants in mink diets in our previous studies [1].

It is important to highlight the major "zootechnical" parameters of the studied minks that are essential for commercial application. The fells dimension A (extra-large) increased by $17.0-57.9 \%$ (Table 5) due to phenozan inclusion into the mink diets. Moreover, under such conditions there were no large fells defects and the amount of the fells without defects also increased (Table 5). The quality score and the prices increased for all mink groups using phenozan in the diets as compared to control group I (Table 5). The obtained data evidenced the high "zootechnical" parameters for all mink groups using phenozan (in their diets) that promotes the mink fur commercial application.

\section{Conclusions}

Thus, inclusion of the special antioxidant phenozan in amount $50-150 \mathrm{mg} /$ day into the mink diet has positive influence on their physiological-biochemical parameters. The optimal phenozan dose is about $100 \mathrm{mg} /$ day per head. Inclusion of phenozan into the mink diet promotes the mink growth and fur dimensions increase which has high importance for animal science and practice.

\section{Competing Interests}

The authors declare that they have no conflict of interest.

\section{Acknowledgments}

The biochemical part of the work presented in the "Results and Discussion" was supported by grant from Russian Scientific Foundation (Project 14-16-00046). The work was performed according to the Russian Government Program of Competitive Growth of Kazan Federal University and subsidy allocated to Kazan Federal University for the state assignment in the sphere of scientific activities.

\section{References}

[1] N. A. Balakirev, Minks Nutrition, Moscow SAVMB Publishing, Moscow, Russia, 2nd edition, 2015.

[2] I. F. F. Benzie, "Evolution of dietary antioxidants," Comparative Biochemistry and Physiology A: Molecular and Integrative Physiology, vol. 136, no. 1, pp. 113-126, 2003.

[3] G. Bjelakovic, D. Nikolova, R. G. Simonetti, and C. Gluud, "Systematic review: primary and secondary prevention of gastrointestinal cancers with antioxidant supplements," Alimentary Pharmacology \& Therapeutics, vol. 28, no. 6, pp. 689-703, 2008.

[4] M. Carocho and I. C. F. R. Ferreira, "A review on antioxidants, prooxidants and related controversy: natural and synthetic compounds, screening and analysis methodologies and future perspectives," Food and Chemical Toxicology, vol. 51, no. 1, pp. 15-25, 2013.

[5] F. Shahidi, Natural Antioxidants. Chemistry, Health Effects, and Applications, The American Oil Chemists Society Publishing, New York, NY, USA, 1997.

[6] R. Kahl, "Synthetic antioxidants: biochemical actions and interference with radiation, toxic compounds, chemical mutagens and chemical carcinogens," Toxicology, vol. 33, no. 3-4, pp. 185228, 1984.

[7] J. Pokorný, N. Yanishlieva, and M. Gordon, Antioxidants in Food Practical Applications, Woodhead Publishing, New York, NY, USA, 2001.

[8] S. Yu. Zaitsev and Yu. V. Konopatov, Animal Biochemistry: Fundamental and Clinical Issues, Lan' Publishing, St. Petersburg, Russia, 2nd edition, 2005.

[9] E. Giacobini and R. E. Becker, Alzheimer's Disease: Therapeutic Strategies, Springer, Berlin, Germany, 2012.

[10] A. P. Khokhlov and K. N. Yarygin, "Specific binding of ${ }^{3} \mathrm{H}-$ phenozan, a synthetic screened phenolic antioxidant with isolated rat enterocytes," Bulletin of Experimental Biology and Medicine, vol. 105, no. 5, pp. 652-654, 1988.

[11] A. A. Prokopov, L. V. Shukil', and A. S. Berlyand, "Studying phenozan acid metabolism in rabbits," Pharmaceutical Chemistry Journal, vol. 40, no. 2, pp. 61-62, 2006.

[12] C. F. Børsting, R. M. Engberg, K. Jakobsen, S. K. Jensen, and J. O. Andersen, "Inclusion of oxidized fish oil in mink diets 1 . The influence on nutrient digestibility and fatty-acid accumulation in tissues," Journal of Animal Physiology and Animal Nutrition, vol. 72, no. 1-5, pp. 132-145, 1994. 
[13] A. Brandt, C. Wolstrup, and T. K. Nielsen, "The effect of dietary dl-alpha-tocopheryl acetate, sodium selenite and polyunsaturated fatty acids in mink (Mustela vison)," Journal of Animal Physiology and Animal Nutrition, vol. 64, no. 1-5, pp. 280-288, 1990.

[14] R. M. Engberg, K. Jakobsen, C. F. Børsting, and H. Gjern, "On the utilization, retention and status of vitamin $\mathrm{E}$ in mink (Mustela vison) under dietary oxidative stress," Journal of Animal Physiology and Animal Nutrition, vol. 69, no. 1-5, pp. 66-78, 1993.

[15] A. Tauson and M. Neil, "Varied dietary levels of biotin for mink in the growing-furring period," Journal of Animal Physiology and Animal Nutrition, vol. 65, no. 1-5, pp. 235-243, 1991.

[16] A. Tauson, "High dietary level of polyunsaturated fatty acids and varied vitamin $\mathrm{E}$ supplementation in the reproduction period of mink," Journal of Animal Physiology and Animal Nutrition, vol. 72, no. 1-5, pp. 1-13, 1994.

[17] S. Y. Zaitsev and M. N. Shaposhnikov, "The photoactivated fluorescent dye for probing cellular organelles and lipid monolayers," The FEBS Journal, vol. 282, no. 1, p. 148, 2015. 

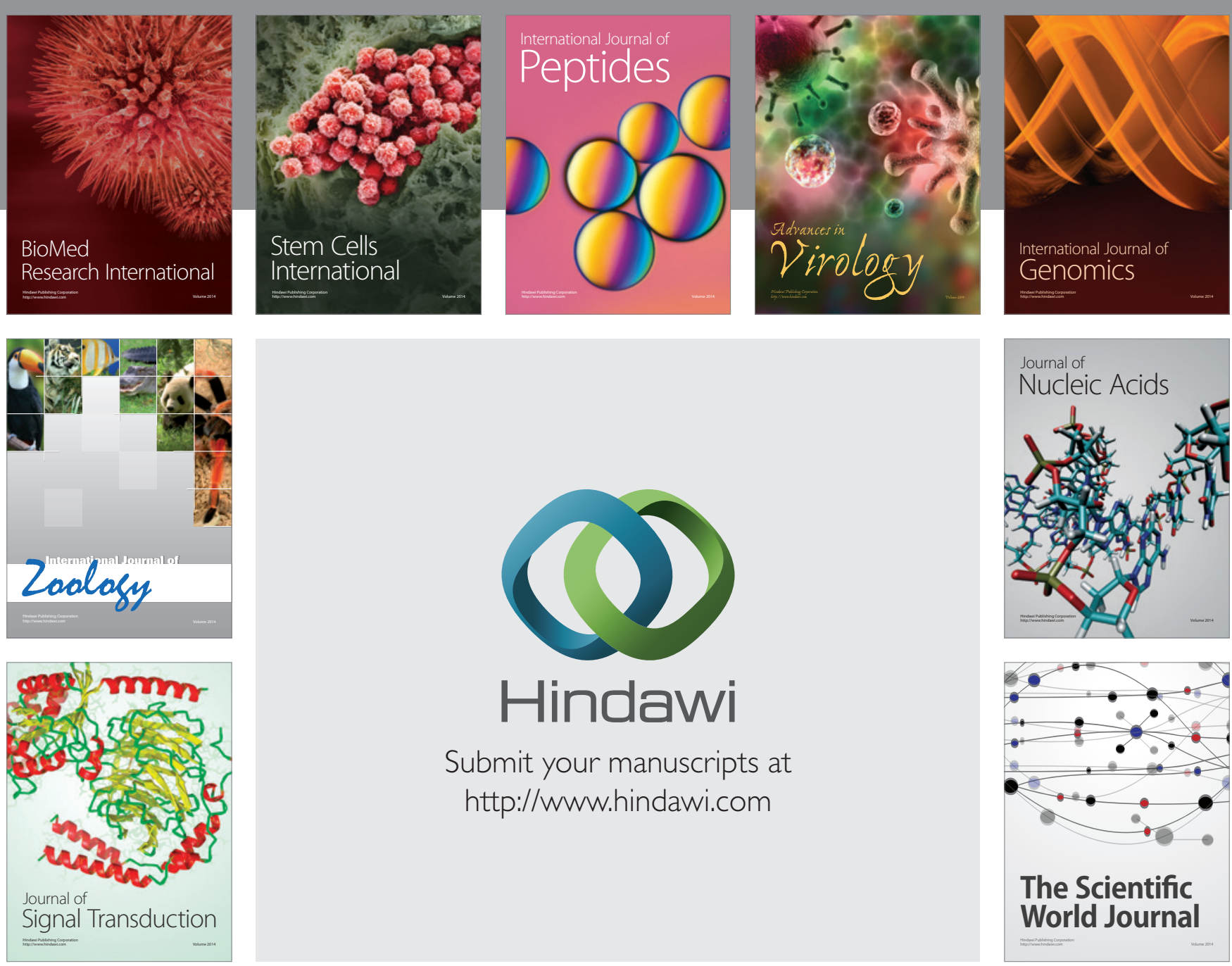

Submit your manuscripts at

http://www.hindawi.com
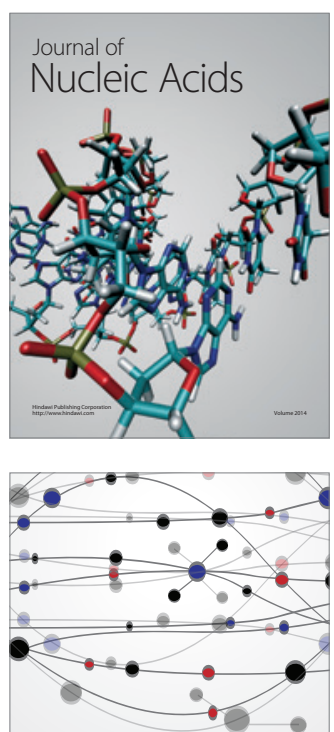

The Scientific World Journal
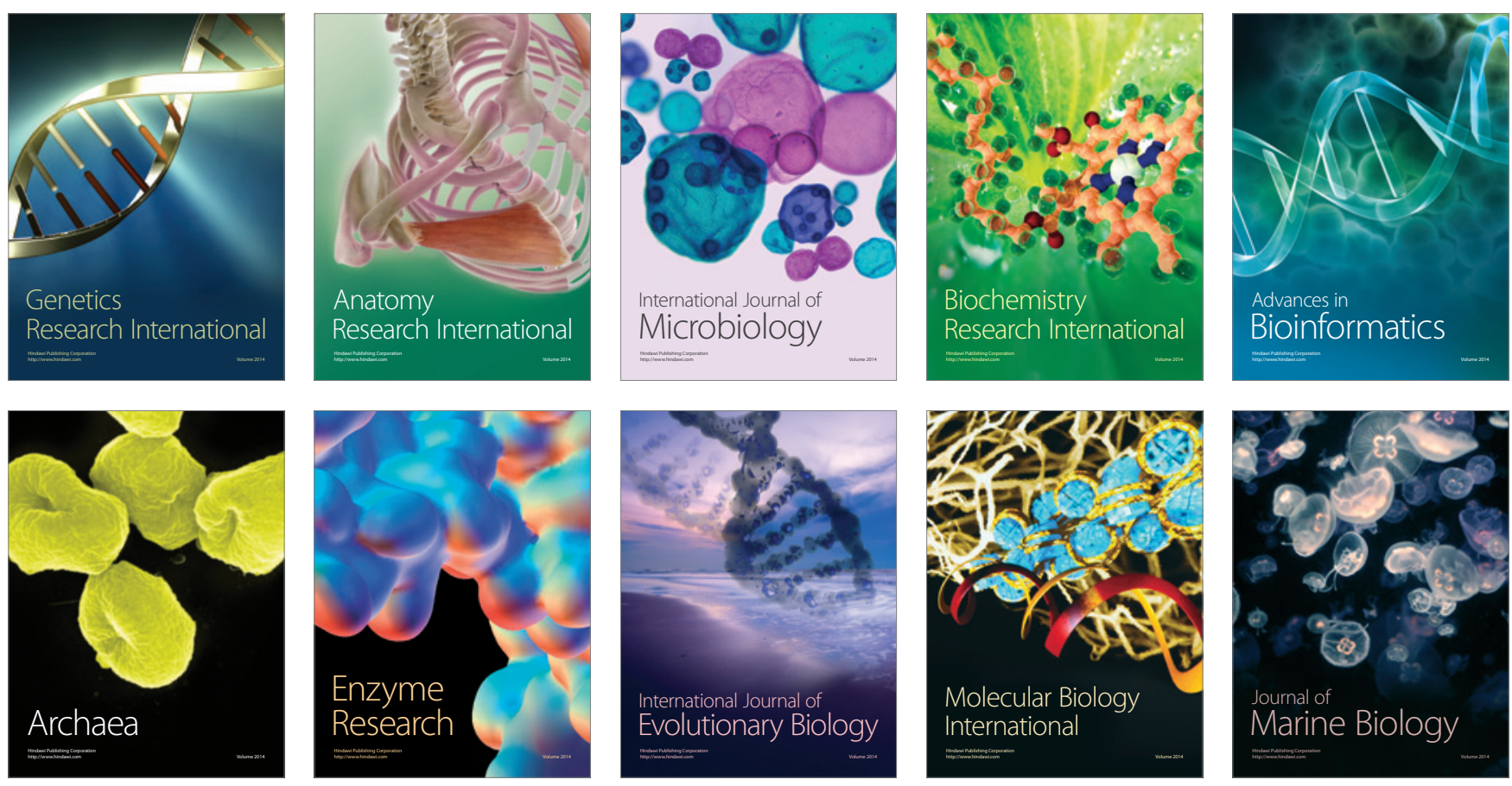